\title{
NATURE OF RESISTANCE OF LYAMUNGU HYBRIDS TO Colletotrichum kahawae STRAINS
}

\author{
KILAMBO D.L. ${ }^{*}$, SILVA M. ${ }^{2}$, MABAGALA R.B. ${ }^{3}$, VARZEA V.M.P. ${ }^{2}$ AND TERI J.M. ${ }^{1}$ \\ ${ }_{1}^{1}$ Tanzania Coffee Research Institute P.O.Box 3004 Moshi, Tanzania. \\ 2Instituto de Investigação Científica Tropical, Quinta do Marquês 2784-505 Oeiras, Portugal. \\ 3Sokoine University of Agriculture P.O. Box 3005 Morogoro, Tanzania. \\ *Corresponding Author: Email- dkilambo@gmail.com
}

Received: February 18, 2013; Accepted: March 04, 2013

\begin{abstract}
Nature of resistance of Lyamungu coffee hybrids to coffee berry disease (CBD) caused by Colletotrichum kahawae were evaluated using conidia germination on cuticular wax extracted from the hybrids, stimulatory effects on the infection of the pathogen, and evidence of genetic resistance on studies using hypocotyls and green berries in the field. Significant differences ( $£ £ 0.05$ ) were found between the levels of conidia germination on the extracted wax of the coffee genotypes. Nine coffee genotypes showed no conidia germination and five showed conidia germination percentage of below $20 \%$. Conidial germination percentage levels of up to $90 \%$ were found on CBD susceptible variety N39. Light micrographs showed that hyphal growth of $C$. kahawae strains were restricted in epidermal cells and cortex of CBD resistant genotypes 20498 and 20509. Callose and thick walls were observed in cortex cells of resistant genotypes 20498 and 20509 . Field evaluation also revealed same genotypes which exhibit highest levels of CBD resistance. In order to understand resistance of Lyamungu coffee hybrids, pathogenicity of $26 \mathrm{C}$. kahawae strains from different eco-agricultural zone in Tanzania was studied under laboratory conditions. Pathogenicity tests both on detached green coffee berries and hypocotyls drew a distinction between highly and less pathogenic strains. The $C$. kahawae strain 2006/14 was found to be the most pathogenic because it showed high sporulation capacity and also induces CBD symptoms 3 days after infection both on green coffee berries and hypocotyls.
\end{abstract}

Keywords- Nature of resistance, CBD pathogenicity, Lyamungu coffee hybrids

Citation: Kilambo D.L., et al. (2013) Nature of Resistance of Lyamungu Hybrids to Colletotrichum kahawae Strains. International Journal of Biotechnology Applications, ISSN: 0975-2943 \& E-ISSN: 0975-9123, Volume 5, Issue 1, pp.-137-146.

Copyright: Copyright@2013 Kilambo D.L., et al. This is an open-access article distributed under the terms of the Creative Commons Attribution License, which permits unrestricted use, distribution and reproduction in any medium, provided the original author and source are credited.

\section{Introduction}

Coffee berry disease (CBD) caused by Colletotrichum kahawae Waller and Bridge is the most serious disease of Arabica coffee (Coffea arabica L.) in Tanzania. The pathogen infect all stages of the crop from flowers to ripe fruits, but maximum crop losses occur following infection of green berries initially forming dark sunken lesions and eventually the rotting of the berry. However, according to the history of $\mathrm{CBD}$, the genetic resistance appeared complete in Coffea canephora and partial in C. arabica. Hocking [11] demonstrated that there is a notable variation in CBD resistance within coffee varieties. Mulinge [16], on the other hand, found out that the susceptibility of berries to CBD varies with the age of the crop; berries are most susceptible when they are between 4th and 16th weeks after flowering, and at ripening stage but pin heads and hard mature berries ( $\geq 16$ th week) are resistant. Differences in the resistance of coffee trees to CBD are frequently observed under laboratory and field conditions. The high levels of resistance were found in Rume Sudan [32-34].

Studies carried out in Kenya by Van der Vossen and Walyaro [32] concluded that coffee resistance to CBD appears to be controlled by major genes on three different loci. The highly resistant variety Rume Sudan carries the dominant $\mathrm{R}$ - and recessive k-genes. Hibrido de Timor carries one gene for CBD resistance on the Tlocus. In Arabica coffee resistance mechanism to C. kahawae are both preformed and induced, and operate at different stages of pathogenesis [10]. The coffee berry cuticle could act as a physical barrier to the penetrating pathogen. Masaba \& van der Vossen [15] accounts for scab formation on the berry surface as resulting from cork berries formation. Similar studies on the occurrence and possible role of fungi toxic compounds either preformed or induced in coffee berries with $C$. kahawae $[5,6,11]$. They concluded that coffee berries posses inherent antifungal compounds that counteract infection from C. kahawae species. Accordingly, Steiner [30] reported that surface wax extracted with chloroform from green berries of varieties Rume Sudan and Blue Mountain contain substances that decrease significantly conidial germination of $C$. kahawae.

Breeding programme on CBD resistance was initiated in Tanzania in early 1960s; and by 1990s, there were a number of Lyamungu coffee hybrids which were reported to have acquired resistant genes to $C$. kahawae [17]. These hybrids when tested for reaction 
to C. kahawae strains from Lyamungu (TZ 005) between 1992 and 1993 using an attached berry technique reveal a number of coffee lines with resistance to the pathogen [18]. However the nature of resistance of these coffee hybrids needs to be confirmed using different $C$. kahawae strains existing in coffee growing regions in Tanzania.

\section{Materials and Methods \\ Nature of Resistance of Lyamungu Hybrids to Colletotrichum kahawae}

The current study which focused on the influence of Colletotrichum kahawae strains on physical defense mechanisms of coffee, was done to establish whether Lyamungu hybrids possess cuticular wax on green berries that inhibit spore germination of Colletotrichum kahawae, whether they have stimulatory effect on the infection process and whether they have field resistance by applying artificial inoculation using four $C$. kahawae strains on the hybrids.

\section{The Influence of Surface Wax from Green Berries on Spore Germination of Colletotrichum kahawae}

Germination of spores of the C. kahawae strains (post-penetration stages) was evaluated on surface wax layer extracted from green coffee berries of hybrid coffee lines. From each of the hybrid lines [Table-1], 10 green berries approximately 17 weeks after flowering were collected for wax extraction. The 10 berries from each selection were shaken for 15 seconds in $100 \mathrm{ml}$ chloroform which was then evaporated off in a water bath at $40^{\circ} \mathrm{C}$. The residue was redissolved in $5 \mathrm{ml}$ chloroform and filtered using Whatman no. 1 filter paper. Four $5 \mathrm{ml}$ drops of wax were placed on the slides cleaned with acetone replicated three times. After drying, the wax deposits were covered with one $5 \mathrm{ml}$ drops of an aqueous suspension containing $2 \times 10^{6}$ conidia per $\mathrm{ml}$ of $C$. kahawae of isolate 2006/16. Tween 80 ( 0.1 per cent) was added to improve wetting of the wax layer and enhancing conidial germination. The slides were incubated in damp chambers for $16 \mathrm{hrs}$ at $22^{\circ} \mathrm{C}$. In each drop the number of germinated conidia out of 50 was recorded. Rume Sudan VC298 and Hibrido de Timor1343 were included as resistant and N39 as susceptible controls.

Table 1- Coffee lines resistant to Colletotrichum kahawae strain TZ 005 from Tanzania

\begin{tabular}{|ll|}
\hline Code & Parentage \\
20497 & Kaffa X (N 39 X OP 729) X HdT \\
20498 & (N 39 X HdT 1343) X Rume Sudan \\
20499 & (N 39 X Kaffa) X HdT \\
20500 & Rume X (N 39 X HdT) \\
20501 & (N 39 X OP 729) X HdT) X Illubabor \\
20502 & (N 39 X HdT) X Illubabor \\
20503 & (Bourbon X Kaffa) X (Rume x HdT) x HdT 1343 \\
20504 & (N 39 X OP 729) X HdT) X N 39 \\
20505 & (N 39 X OP 729) X HdT) X N 39 \\
20506 & (N 39 X OP 729) X HdT) X Kent \\
20507 & KP 423 X HdT \\
20508 & (N 39 X OP 729) X HdT 1343) X N 39 X HdT 1343 \\
20509 & Rume Sudan VC 298 \\
20510 & Hibrido de Timor 1343 \\
20511 & N 39 \\
20512 & KP 423 \\
\hline
\end{tabular}

Stimulatory Effect on the Infection of Colletotrichum kahawae in Coffee Hypocotyls

Coffee genotypes 20498, 20509 and 20511 at the hypocotyl stage (5-6 weeks after germination) were spot inoculated with a $5 \mathrm{ml}$ drop of C. kahawae strains Que 2 and T3 (2006/14). After inoculation, the coffee hypocotyls were maintained at $100 \%$ relative humidity in darkness for 24 hrs. Cross sections of the infected hypocotyl fragments at a thickness of $20-25 \mathrm{~mm}$ were made with a freezing microtome stained and mounted in a cotton blue lactophenol solution to evaluate fungal post-penetration stages. Hyphal length inside hypocotyl tissues were estimated by counting the number of cortex layers penetrated using a micrometric eyepiece. The data were recorded from at least 20 infection sites per genotype at 24, 48 and $72 \mathrm{hrs}$ after inoculation. To detect callose deposition on coffee hypocotyls, cross sections of infected tissues were placed in $0.07 \mathrm{M}, \mathrm{pH} 8.0$ phosphate solution $\left(\mathrm{K}_{2} \mathrm{HPO}_{4}\right)$ for $10 \mathrm{~min}$ and then transferred into a $0.01 \%$ solution of aniline blue in the phosphate solution for $10 \mathrm{~min}$ before being mounted in the same solution. Callose deposition on coffee hypocotyls was identified by bright yellow fluorescence light, where absence of fluorescence was considered as negative.

\section{Evaluation of 16 Coffee Lines for Resistance to Colletotrichum kahawae Strains}

A completely randomize design (CRD) arranged in a split-plot was used in the study. Four $C$. kahawae strains represented the main treatments and 16 genotypes were arranged as sub-plots with three replications. Forty hypocotyls (5-6 weeks old) of 16 coffee genotypes were spray inoculated twice with $C$. kahawae suspensions $\left(2.0 \times 10^{6} \mathrm{spores} / \mathrm{ml}\right)$ at $48 \mathrm{hrs}$. intervals following [33] procedures. A temperature range of $22-24^{\circ} \mathrm{C}$ was used during the first four days of incubation to allow infection, while relative humidity in the boxes was maintained at $100 \%$. Thereafter, inoculated coffee hypocotyls were incubated for three weeks at $19-20^{\circ} \mathrm{C}$. Hypocotyls were individually scored for CBD symptom development using a scale of $0-4$ ( $0=$ absence of symptoms, $1=$ one or two small brownish chlorotic lesions, 2 = coalescence brownish lesions, 3 = abundant black lesions, 4 = dead hypocotyls), developed by Van der Graaff [31]. The scoring days were at 7,14 and 21 days at Lyamungu, Moshi, Tanzania and 3, 6, 9, 12, 15, 18 and 21 days at CIFC, Portugal. Different rating interval was attributed to a modification of the inoculation and assessment procedures done at CIFC [35]. Categories of reaction Disease Index Reaction (DIR) of the coffee hybrids were determined.

For each genotype DIR was determined using the formula shown below [25]:

Where:

$$
D I R=25 \frac{\sum i \times n i}{i n}
$$

$I=$ numerical value of disease description

$n i=$ number of hypocotyls in disease description

$n=$ number of hypocotyls in all description

Resistance categories were classified as; resistant (DIR 0-25), moderately resistant (DIR 26-50), moderately susceptible (DIR 5175), and susceptible (DIR 76-100).

\section{Evaluation of 16 Coffee Genotypes Under Field Conditions}

Ten mature bearing coffee trees of 21 years old per genotype were artificially inoculated using four virulent strains of $C$. kahawae. Strains 2006/8, 2006/12, 2006/14 and 2006/22 of C. kahawae were inoculated to a set of two branches having five to six berry clusters per branch (about 40 berries per cluster) of green expanding coffee berries at 8 to 12 weeks old. The concentration of $2 \times 10^{6} \mathrm{spores} / \mathrm{ml}$ of spore suspension was used. Each coffee branch was sprayed twice at $48 \mathrm{hrs}$. intervals using the method described by Kilambo, et al [12]. The assessment of CBD development was done by counting 
the number of CBD coffee infected berries against that of uninfected berries after 7, 14 and 21 days after the second inoculation. Coffee genotypes 20511 and 20512 which were N39 and KP423, respectively, and which were susceptible to $C$. kahawae were also used as controls. The mean CBD incidence for each variety was calculated and used in the correlation analysis together with the results obtained from hypocotyls reaction.

\section{Determination of Pathogenicity Levels of Colletotrichum kaha- wae}

\section{CBD Pathogenicity Levels on Green Coffee Berries}

The pathogenicity of $C$. kahawae was tested on 20 fully expanded soft green berries ( $£ 14$ weeks old from the date of flowering) of the susceptible variety N39. Coffee berries were surface sterilized, placed on damp sterilized sand in plastic boxes and inoculated with a $0.02 \mathrm{ml}$ drop of the standard $C$. kahawae spore suspension using a pipette. The inoculated green coffee berries were incubated at $25^{\circ} \mathrm{C}$ and observed for CBD symptom development for 14 days. Parameters on the percentage of infected berries; days for first symptoms appearance, enlargement of lesions, and appearance of sporulation and sporulation capacity after 10 days were recorded. Sporulation capacity was determined by counting spores per $\mathrm{ml}$ using haemocytometer.

\section{CBD Pathogenicity Determination on Hypocotyls}

Seeds of N 39 were planted with the parchment on, in plastic bags containing a sterilized soil mixture made up of compost and sand at a ratio of 2:1 respectively. The plastic bags were kept under moist conditions in the laboratory at a temperature of around $25^{\circ} \mathrm{C}$. After two weeks of pre-germination, coffee seedlings (40 seedlings per tray) were planted in plastic trays.

\section{Inoculum Preparation of Colletotrichum kahawae Strains and Inoculation}

Spore suspensions of tentative C. kahawae were prepared from 17day-old cultures on MEA. Five $\mathrm{ml}$ of sterile distilled water were pipetted on each culture to dislodge the spores. A sterile scalpel was used to scrape off colonies from the agar surface; the mixture was placed in sterile conical flasks and shaken well by hand to dislodge the spores further. The mixture was then filtered to obtain C. kahawae spore suspensions. Spore concentrations were estimated using the haemocytometer and calibrated to $2.0 \times 10^{6}$ spores $/ \mathrm{ml}$ [33]. Forty hypocotyls (5-6 weeks old) from 16 coffee genotypes were spray inoculated twice at $48 \mathrm{hr}$ intervals with suspensions of $C$. kahawae using the method described by Van der Vossen, et al [33]. Strains of C. kahawae 2006/14, 2006/22, 2006/12 and 2006/8 collected from Tanzania based on their pathogenic levels were used to inoculate 16 coffee genotypes. The $C$. kahawae strains $\mathrm{Ca} 1$ (Cameroon), Que2 (Kenya), and Z9 (Zimbabwe) were also used to assess nature of resistance of the same genotypes. In order to allow successful infection by $C$. kahawae, the seedlings were kept in propagation boxes at a temperature ranging from 22 to $24^{\circ} \mathrm{C}$ for the first four days after inoculation, and relative humidity in the boxes was maintained at $100 \%$ by spraying sterile distilled water three times a day (morning, mid-day and evening). After four days of incubation, the temperature was maintained at $19-20^{\circ} \mathrm{C}$ for the incubation period of three weeks. The numbers of infected seedlings per isolate were recorded at 7,14 and 21 days and the pathogen was re-isolated from the infected seedlings to maintain isolate viability.

\section{Sporulation Capacity on Green Coffee Infected Berries}

Spore suspensions of $C$. kahawae isolates were obtained from clean sporulating 20 green berries by shaking them in a conical flask containing $5 \mathrm{ml}$ of sterile distilled water. The suspensions were filtered through sterile paper towel. Spore concentration per ml was calibrated using a haemocytometer.

\section{Results and Discussion}

\section{Determination of the Nature of Resistance to Colletotrichum kahawae}

\section{Influence of Surface Wax from Green Berries on Germination of Colletotrichum kahawae}

The percentage germination of $C$. kahawae on the surface waxes of 12 coffee hybrids was compared with the field resistance of two known resistant coffee genotypes Rume Sudan (VC 298) (20509) and Hibrid de Timor 1343 (20510), N39 (20511) and KP 423 (20512) susceptible genotypes. The results obtained are presented in [Fig-1].

The results in [Fig-1] shows that there were highly significant differences (P£0.05) between the level of conidial germination on the wax of coffee genotype N 39, KP 423, the 12 hybrids, 20509 and 20510. Conidial germination percentage was highest on wax extract from coffee genotype 20511 than the rest. Germination percentage of conidia and disease resistance in the field were positively correlated $\left(r=0.85^{\star * *}\right)\left(P<0.05\right.$, d.f 14; $r_{t}=0.497, P £ 0.05 ; r_{t}=0.623$, $P<0.01)$.

The wax surface extracted with chloroform from green berries of the 12 coffee hybrids suggest that they contain substances that decrease conidia germination. Correlation between conidia germination and field resistance was positive and significant $\left(r=0.85^{* * *}\right)$ $(P<0.05)$, indicating that cuticular substances may contribute to the high levels of field CBD resistance. The study results revealed that CBD resistance of Lyamungu coffee hybrids is partly being contributed by wax surface on green coffee berries. Similar results were reported by Steiner [30] who found a significant decrease of conidia germination in the wax surface extracted from Rume Sudan. Other authors confirm that the cuticular wax layer has influence on the fungal growth, hyphal anastomosis and the production of penetration pegs from hyaline appressorium on green and red pepper and tomatoes $[7,20]$.

\section{Nature of the Resistance Coffea Arabica to Colletotrichum ka- hawae Strains at Hypocotyls Stage}

Five to six week old hypocotyls of coffee genotypes 20498, 20509 and 20511 were inoculated with C. kahawae strains Que 2 and T3. The disease intensity reaction (DIR) and proportion of scabs and active lesions on the coffee hypocotyls are presented in [Table-2]. The DIR of coffee genotypes 20498 and 20509 indicated that the genotypes were moderately resistant to CBD, but coffee genotype 20511 was susceptible [Table-2]. The two genotypes (20498 and 20509) had higher proportions of scab lesions than genotype 20511 , which had high proportions of active CBD lesions. The presence of scab CBD lesions formed resistant or moderately resistant coffee genotypes suggesting that the mechanism by which further invasion of the CBD pathogen is blocked $[11,15]$. Recently findings by Chen, et al [5] revealed that green coffee berries posses inherent antifungal compounds that counteract the infection of coffee by C. kahawae strains. Such antifungal compounds may exist in Ly- 
amungu coffee genotypes that contributed to CBD resistance. However, more studies are needed to confirm the involvement of antifungal compounds in the resistance of Lyamungu coffee genotypes to CBD.

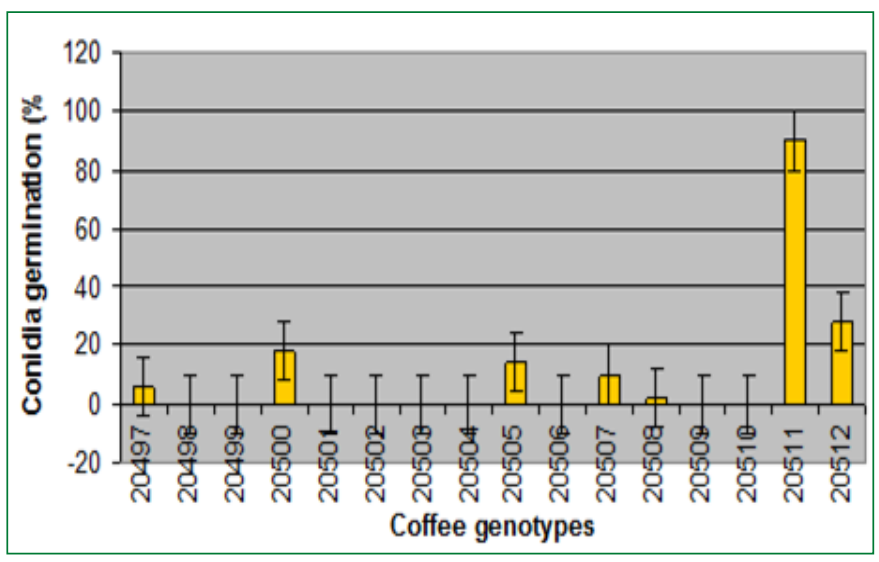

Fig. 1- Germination percentage of conidia of Colletotrichum kahawae $(2006 / 16)$ strain on wax surface extracted from berries of different genotypes of Coffea arabica

Table 2- The reaction of three coffee genotypes to two Colletotrichum kahawae strains (Que 2 and T3)

\begin{tabular}{lcccc} 
Coffee Genotype & $\begin{array}{c}\text { Disease Intensity Reaction* } \\
\text { (DIR) }\end{array}$ & $\begin{array}{c}\text { Proportion of scab and active } \\
\text { lesions (\%)* }\end{array}$ \\
& Que. 2 & T3 & Que. 2 & T3 \\
\hline 20498 & 37 & 49 & Scabs $>90$ & Scabs $>90$ \\
20509 & 36 & 48 & Scabs $>95$ & Scabs $>95$ \\
20511 & 98 & 96 & Actives 100 & Actives 100 \\
\hline
\end{tabular}

${ }^{*}$ Assessment was done 15 days after inoculation

DIR = 0-25, Resistant; 26-50, Moderately Resistant; 51-75 moderately susceptible; 76-100 susceptible. Que2 = Kenyan C. kahawae strain, T3 = Tanzanian C. kahawae strain (2006/14)

Actives $=$ active lesions, Scab $=$ scabs

\section{Growth of Colletotrichum kahawae in Epidermal and Cortex Cells of Hypocotyls}

The results in [Table-3] show that the post-penetration of C. kahawae hyphae (24, 48 and 72 hrs.) between the three coffee genotypes was not significantly different from each other $(P<0.05)$. However, the penetration of $C$. kahawae strain Que 2 was deeper in genotype 20511 than it was in genotypes 20498 and 20509 [Fig-2].

Evidence of the Presence of Phenolic Compounds in Lyamungu Coffee Hybrids as a Source of Resistance to Colletotrichum kahawae

Infection sites per genotype were also located and fungal growth inside epidermal and cortex cells of the hypocotyls determined at 7 and 14 days after inoculation with T3 and Que 2 strains. The penetration of C. kahawae in each coffee genotype is shown in [Fig-3a] to [Fig-3e]. Cumulative data on the fungal penetration of $C$. kahawae inside hypocotyls were higher in the susceptible coffee genotype 20511 than they were in the resistant coffee genotype 20498 and 20509. [Table-3], [Fig-2]. Light micrographs also showed that hyphal growth of $C$. kahawae strains was restricted in epidermal cells and cortex for genotypes 20498 and 20509 [Fig-3a] to [Fig-3e]. On the other hand, setae, arcevuli and sporulation were observed on genotype 2051114 days after inoculations [Fig-3e]. Similar results were reported by Silva, et al [28] who found that fungal hyphal length inside host tissues was significantly lower in the resistant coffee genotypes than in the susceptible ones. This might be because resistant plants develop defense mechanisms against attack by the pathogen [14,29]. In this respect, Masaba and van der Vossen [15] reported that scab formation on the green coffee berry surface is due to cork barrier formation which limits fungal hyphal growth inside the plant tissue. The formation of setae, arcevuli and sporulation after 14 days on genotype 20511 indicate susceptibility. The data confirm that Lyamungu hybrids can be good sources of CBD resistance.

Table 3- Post penetration growth of Colletotrichum kahawae strain Que 2 in hypocotyls of three coffee genotypes

\begin{tabular}{lcccccccc|}
$\begin{array}{l}\text { Duration } \\
\text { (hours) }\end{array}$ & $\begin{array}{c}\text { Mean Fungal Hyphal Growth } \\
\text { Inside Hypocotyls Tissues }(\mathbf{m m})\end{array}$ & $\begin{array}{c}\text { DMRT } \\
(\mathbf{P}<0.05)\end{array}$ & SE Variance & S.D Mean \\
\hline & 20498 & 20509 & 20511 & & & & & \\
24 & 6.95 & 11.25 & 12.2 & 18.8 & 1.6 & 7.8 & 2.3 & 10.1 \\
48 & 10.15 & 12.25 & 19.7 & & 2.9 & 25.2 & 5 & 14 \\
72 & 10.55 & 13.2 & 21.7 & & 3.4 & 35.2 & 5.9 & 15.2 \\
Cumulative & 27.65 & 36.7 & 53.6 & & & & & \\
\hline
\end{tabular}

Key: 20498, 20509 and $20511=$ Coffee genotypes, DMRT = Duncans' Multiple Range Test, SE = Standard error, S.D = Standard deviation, Mean followed by the same letter within the same column does not differ significantly following the mean separation by Duncans' Multiple Range Test

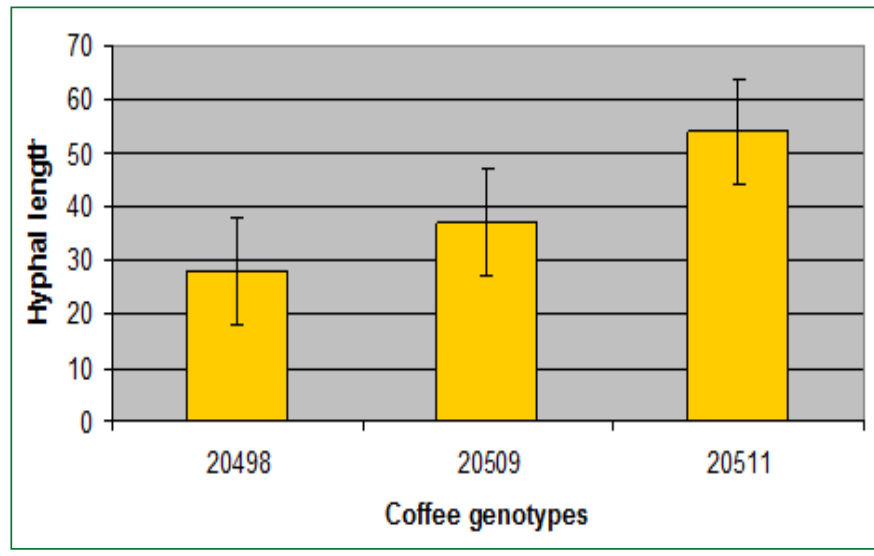

Fig. 2- Hyphal growth length ( $\mathrm{mm}$ ) of Colletotrichum kahawae strain Que in coffee hypocotyl tissues of resistant (20498 and 20509) and susceptible genotype (20511)

Light micrographs were used to detect callose deposition of coffee hypocotyls. The data presented in [Fig-4a] to [Fig-4d] revealed the presence of phenolic compounds enabling callose formation at infection sites in coffee genotypes 20498 [Fig-4a], coffee genotype 20498 showing callose formation and necrotic host cells [Fig-4b] and coffee genotype 20509 showing callose formation and thick walls [Fig-4c]. Coffee genotype 20511 showed callose formed around intracellular hyphae, but fungal hyphal growth of $C$. kahawae invading all over cortex cells [Fig-4d].

The use of histological characterization has been reported as being useful in detecting levels of resistance to species of root-knot nematodes related to accumulation of phenolics in Capsicum annun [24]. Silva, et al [26] reported that deposition of callose (a polysaccharide material) around intracellular hyphae is an early host response detected in the resistant genotypes. The authors also reported that thick walls are formed as a result of wall appositions (papillae) and callose (phenolic compounds) being deposited between the plasma membrane and outer wall of epidermal cell, at sites of attempted penetration by $C$. kahawae. More recent studies revealed that epi- 
catechin and catechin present in green coffee berry pericarp of $\mathrm{CBD}$ resistant genotypes may prevent $\mathrm{CBD}$ by inhibiting appressorium penetration [3,4]. However, the amount of epicatechin and catechin present in Lyamungu hybrids requires investigation. These studies confirm further that Lyamungu coffee hybrids have good sources of resistance to $C$. kahawae strains and these can be used to improve the coffee breeding programme.

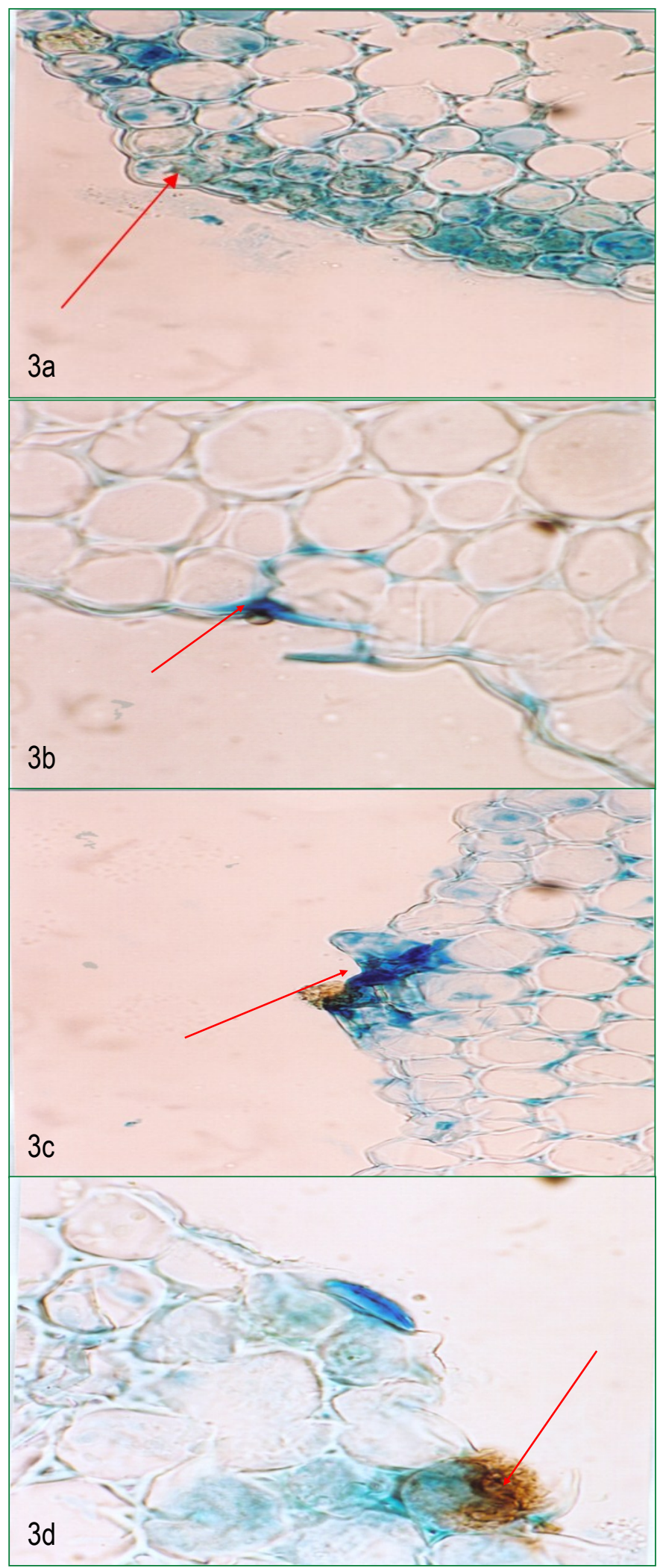

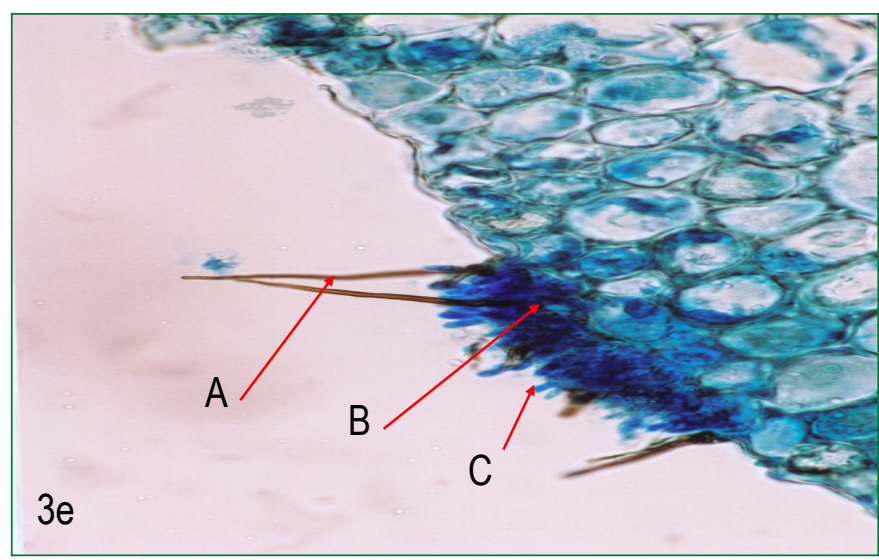

Fig. 3- Light micrographs showing post penetration growth of Colletotrichum kahawae in hypocotyls of coffee genotypes 20498, 20509 and 20511 all at Magnification X40. Hypocotyl sections stained with cotton blue lactophenol. Red arrows point to details below; hyphal growth of Colletotrichum kahawae strain T3 restricted in epidermal cells and $2^{\text {nd }}$ layer of genotype 20498 seven days after inoculation [Fig-3a], Germinated conidia of Qu 2 without extend germtube when inoculated on genotype 20509 fourteen days after inoculation [Fig3b], Necrotic reaction of genotype 20509 caused by reaction of Colletotrichum kahawae strain T3 seven days after inoculation [Fig$3 c]$, Nectrotic reaction of genotype 20509 to Colletotrichum kahawae strain Qu2 fourteen days after inoculation [Fig-3d], Formation of setae (A), arcevuli (B) and sporulation (C) and high hyphal growth caused by Colletotrichum kahawae strain T3 fourteen days on genotype 20511 [Fig-3e].

\section{Identification of Lyamungu Coffee Hybrids for Resistance to Colletotrichum kahawae Strains}

Colletotrichum kahawae strains varying in pathogenicity were used to inoculate $16 \mathrm{C}$. arabica varieties. Both hypocotyls (5-6 week old) and berries in mature bearing plants ( $4^{\text {th }}$ to $14^{\text {th }}$ week) of the same coffee genotypes were inoculated with $\mathrm{CBD}$ spore suspension at 2 $x 10^{6} \mathrm{spore} / \mathrm{ml}$. For the hypocotyls test, one experiment was done at Lyamungu using C. kahawae strains 2006/14, 2006/22, 2006/12 and 2006/8; the results are presented in [Table-4] and [Table-5]. A second experiment was done at CIFC, Portugal using $C$. kahawae strains Ca1, Que2 Z9 and T3 (2006/14); the results are presented in [Table-6]. A rating scale of $0-4$ was used to score reaction on coffee hypocotyls per genotype. The mean percentage of seedlings that resisted C. kahawae infection per genotype was recorded 21 days after inoculation. Green coffee berries at 4 to 14 weeks old were inoculated at Lyamungu using strains 2006/14, 2006/22, 2006/12 and 2006/8, and the results are presented in [Table-7]. The mean percentage of the infected green berries per genotype was finally recorded 21 days after inoculation.

The results in [Table-4] (data scored using 0-4 rating scale, then arc sine transformed) present the reactions of $C$. kahawae strains 2006/14, 2006/22, 2006/12 and 2006/8 on coffee hypocotyls 21 days after inoculation. Coffee genotypes 20498 and 20509 significantly resisted CBD (P£ 0.05) as opposed to 20511. Likewise, the data on the percentage of coffee hypocotyls of the same genotypes that were resistant to $C$. kahawae strains are presented in [Table-5]. The percentage of coffee hypocotyls per genotype resistant to CBD varied significantly $(P £ 0.05)$. Where as coffee genotypes 20498 and 20509 were resistant to all four C. kahawae strains (2006/14, 2006/22, 2006/12 and 2006/8), genotype 20511 was the most sus- 
ceptible to almost all $4 \mathrm{C}$. kahawae strains. Furthermore, the DIR of 20498 and 20509 were observed to be resistant to CBD [Table-5].

The results from [Table-4] and [Table-5] show that coffee genotype 20498 and 20509 were resistant to CBD, suggesting a possibility of being used by coffee growers across coffee ecosystems in Tanzania.
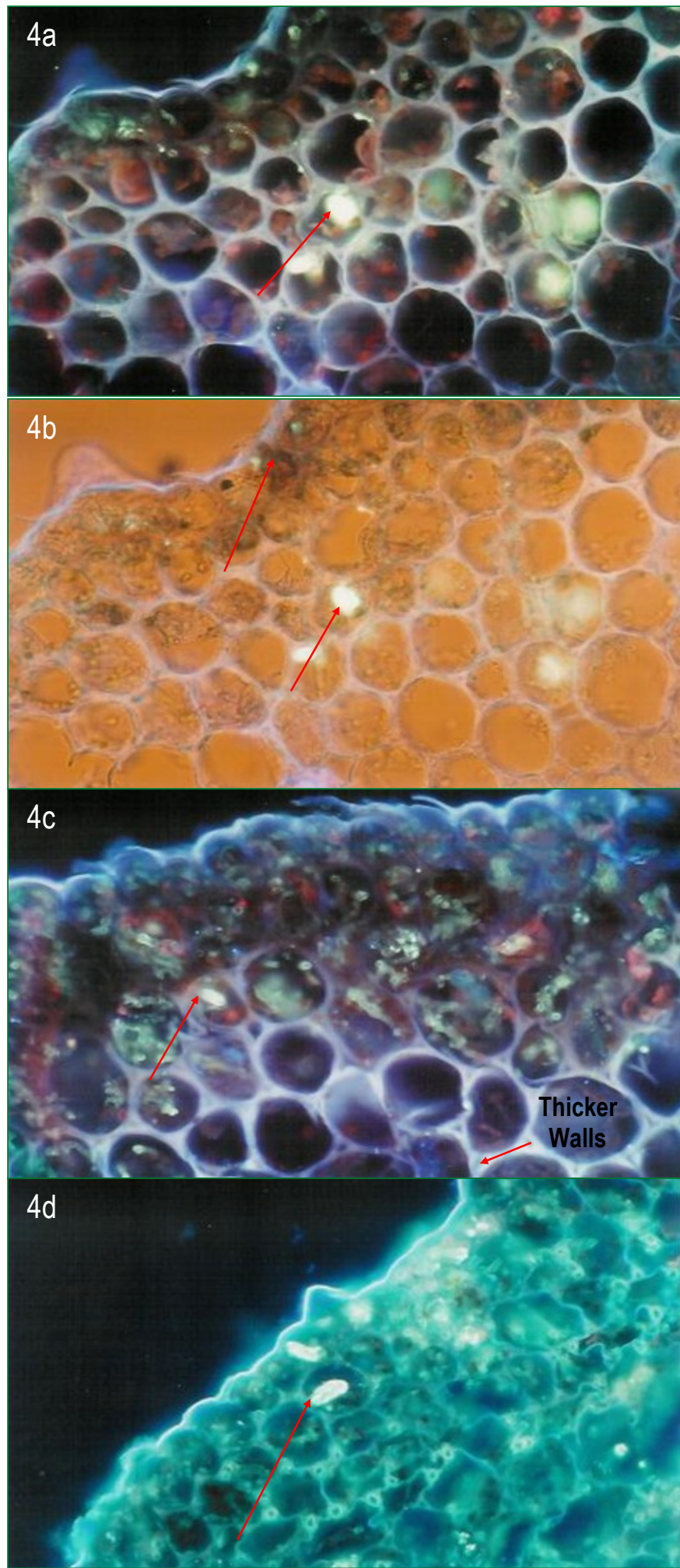

Fig. 4- Light micrographs of callose formation (arrow) in different coffee genotypes 20498 [Fig-4a] and [Fig-4b], 20509 [Fig-4c] and 20511 [Fig-4d] seven days after inoculation (Magnification x 25).
Table 4- Reaction of coffee genotypes to Colletotrichum kahawae strains 21 days after inoculation

\begin{tabular}{lcccc} 
Coffee & \multicolumn{5}{c}{ Colletotrichum kahawae Strains } \\
Genotypes & 2006/14 (T3) & 2006/22 (T12) & 2006/12 (T26) & 2006/8 (T4) \\
\hline 20497 & $7.3 \mathrm{~A}$ & $3.8 \mathrm{ABC}$ & $7.1 \mathrm{ABC}$ & $6.5 \mathrm{AB}$ \\
20498 & $0.0 \mathrm{~B}$ & $0.0 \mathrm{C}$ & $1.9 \mathrm{CD}$ & $0.0 \mathrm{~B}$ \\
20499 & $8.1 \mathrm{~A}$ & $5.7 \mathrm{ABC}$ & $8.7 \mathrm{ABC}$ & $7.9 \mathrm{~A}$ \\
20500 & $5.7 \mathrm{AB}$ & 0 & $2.7 \mathrm{BCD}$ & $4.6 \mathrm{AB}$ \\
20501 & $7.3 \mathrm{~A}$ & 0 & $4.6 \mathrm{BCD}$ & $6.5 \mathrm{AB}$ \\
20502 & $9.9 \mathrm{~A}$ & $6.5 \mathrm{ABC}$ & $9.4 \mathrm{AB}$ & $8.7 \mathrm{~A}$ \\
20503 & $6.5 \mathrm{AB}$ & $0.0 \mathrm{C}$ & $4.6 \mathrm{BCD}$ & $6.5 \mathrm{AB}$ \\
20504 & $8.1 \mathrm{~A}$ & $3.8 \mathrm{ABC}$ & $7.3 \mathrm{ABC}$ & $7.3 \mathrm{~A}$ \\
20505 & $9.9 \mathrm{~A}$ & $7.3 \mathrm{AB}$ & $8.7 \mathrm{ABC}$ & $7.9 \mathrm{~A}$ \\
20506 & $8.1 \mathrm{~A}$ & $1.9 \mathrm{BC}$ & $7.2 \mathrm{ABC}$ & $7.3 \mathrm{~A}$ \\
20507 & $6.5 \mathrm{AB}$ & $0.0 \mathrm{C}$ & $3.8 \mathrm{BCD}$ & $6.5 \mathrm{AB}$ \\
20508 & $8.7 \mathrm{~A}$ & $1.9 \mathrm{BC}$ & $6.7 \mathrm{ABCD}$ & $7.3 \mathrm{~A}$ \\
20509 & $0.0 \mathrm{~B}$ & $0.0 \mathrm{C}$ & $0.0 \mathrm{D}$ & $0.0 \mathrm{~B}$ \\
20510 & $5.7 \mathrm{AB}$ & $1.9 \mathrm{BC}$ & $4.6 \mathrm{BCD}$ & $5.7 \mathrm{AB}$ \\
20511 & $11.5 \mathrm{~A}$ & $9.9 \mathrm{~A}$ & $11.5 \mathrm{~A}$ & $9.9 \mathrm{~A}$ \\
20512 & $8.1 \mathrm{~A}$ & $0.0 \mathrm{C}$ & $8.1 \mathrm{ABC}$ & $5.4 \mathrm{AB}$ \\
DMRT & 6.015 & 6.015 & 6.015 & 6.015 \\
Mean & 6.963 & 2.669 & 6.056 & 6.125 \\
S.E & 0.782 & 0.795 & 0.764 & 0.677 \\
\hline
\end{tabular}

Means followed by same letter within the column do not differ significantly following mean separation by Duncan's multiple range test. CIFC = Centro de Investigacao das Ferrugens do Cafeero, Portugal. $S E=$ Standard error, $S . D=$ Standard deviation Data scored 0-4, then transformed to arc sine

Table 5- Percentage of coffee hypocotyls per coffee genotype that indicated resistance to four Colletotrichum kahawae strains from coffee ecosystems in Tanzania

\begin{tabular}{|c|c|c|c|c|c|c|c|c|}
\hline \multirow{2}{*}{$\begin{array}{l}\text { Genotype/ } \\
\text { strains }\end{array}$} & \multicolumn{2}{|c|}{$2006 / 14$ (T3) } & \multicolumn{2}{|c|}{ 2006/22 (T12) } & \multicolumn{2}{|c|}{ 2006/12 (T26) } & \multicolumn{2}{|c|}{ 2006/8 (T4) } \\
\hline & $\%$ & DIR & $\%$ & DIR & $\%$ & DIR & $\%$ & DIR \\
\hline 20497 & $79.2 \mathrm{D}$ & 48.4 & $100.0 \mathrm{~A}$ & 13 & $84.9 \mathrm{BC}$ & 36.6 & $87.4 \mathrm{C}$ & 35.2 \\
\hline 20498 & $100.0 \mathrm{~A}$ & 8.1 & $100.0 \mathrm{~A}$ & 0 & $100.0 \mathrm{~A}$ & 6.9 & $100.0 \mathrm{~A}$ & 1.7 \\
\hline 2049 & $63.0 \mathrm{~F}$ & 55.5 & $96.7 \mathrm{~A}$ & 21.9 & $71.1 \mathrm{E}$ & 51.6 & $77.5 \mathrm{EF}$ & 49.4 \\
\hline 20500 & $93.0 \mathrm{~B}$ & 30.9 & $99.1 \mathrm{~A}$ & 4.1 & $96.6 \mathrm{~A}$ & 20.7 & $94.1 \mathrm{~B}$ & 20.1 \\
\hline $1<0$ & $79.6 \mathrm{D}$ & 39.9 & $100.0 \mathrm{~A}$ & 6.6 & $85.7 \mathrm{BC}$ & 25.4 & $86.8 \mathrm{C}$ & 29.9 \\
\hline 20502 & $49.6 \mathrm{GH}$ & 74.9 & $90.0 \mathrm{~B}$ & 30.3 & $62.5 \mathrm{~F}$ & 65.9 & $67.5 \mathrm{G}$ & 51.9 \\
\hline 20503 & $86.4 \mathrm{C}$ & 35.6 & $100.0 \mathrm{~A}$ & 3.7 & $88.2 \mathrm{~B}$ & 24.6 & $85.1 \mathrm{CD}$ & 27.9 \\
\hline 20504 & $63.8 \mathrm{EF}$ & 55.2 & $98.3 \mathrm{~A}$ & 17 & $88.0 \mathrm{~B}$ & 37.9 & $75.6 \mathrm{~F}$ & 42.9 \\
\hline 20505 & $45.8 \mathrm{H}$ & 73.8 & $90.0 \mathrm{~B}$ & 38.2 & $55.1 \mathrm{G}$ & 60.6 & $60.0 \mathrm{H}$ & 54.2 \\
\hline 205 & $63.4 \mathrm{EF}$ & 54.1 & $95.5 \mathrm{~A}$ & 14.5 & $85.5 \mathrm{BC}$ & 32.1 & 81.3 DE & 41.9 \\
\hline 20507 & $87.4 \mathrm{C}$ & 28.8 & $99.1 \mathrm{~A}$ & 6.4 & $87.3 \mathrm{~B}$ & 20.8 & $86.7 \mathrm{C}$ & 27.2 \\
\hline 20508 & $68.1 \mathrm{E}$ & 56.1 & $98.1 \mathrm{~A}$ & 13 & $79.3 \mathrm{D}$ & 39.8 & $85.2 \mathrm{CD}$ & 38.7 \\
\hline 20 & $100.0 \mathrm{~A}$ & 0.6 & $100.0 \mathrm{~A}$ & 0 & $100.0 \mathrm{~A}$ & 0.8 & $100.0 \mathrm{~A}$ & 5.2 \\
\hline 2051 & $97.4 \mathrm{AB}$ & 21.2 & $100.0 \mathrm{~A}$ & 10.6 & $97.5 \mathrm{~A}$ & 23.8 & $100.0 \mathrm{~A}$ & 18.6 \\
\hline 20 & 3.31 & 97.9 & $68.7 \mathrm{C}$ & 48.2 & $10.8 \mathrm{H}$ & 93.9 & 40.01 & 73.8 \\
\hline 20512 & $54.1 \mathrm{C}$ & 51.9 & $99.1 \mathrm{~A}$ & 15.8 & $81.7 \mathrm{CD}$ & 38.6 & $85.0 \mathrm{CD}$ & 36.5 \\
\hline DMR & 1.5 & & 1. & & 1. & & & \\
\hline Mean & 25 & & 7. & & 22 & & & \\
\hline S.E \pm & 6.3 & & 1. & & 5. & & 3 & \\
\hline
\end{tabular}

Means followed by same letter within the same column do not differ significantly following mean separation by DMRT test. DIR = Disease Intensity Reaction. DIR 0-25, Resistant; 26-50, moderately resistant; 51-75, moderately susceptible; 76-100 susceptible, $\%=$ Percentage

The data presented in [Table-6] indicate that the percentage of coffee genotypes resistant to CBD differed significantly ( $P £ 0.05$ ). However, there was differential interaction between $C$. kahawae strains Ca1, Que 2, Z9 and T3 (2006/14) and C. arabica genotypes. Furthermore, the results on the DIR indicate interaction between $C$. kahawae strains and coffee genotypes. Coffee genotype 20509 was resistant to C. kahawae strains Ca1, Que2, and Z9; however, it was susceptible to strain T3. Similarly, coffee genotype 20498 indicated 
resistance to strains Ca1, Que2 and Z9 but it was susceptible to strain T3. Coffee genotype 20510 shows susceptibility to strain $\mathrm{Ca} 1$, but it was resistant to the three strains of $C$. kahawae. These data imply that the $C$. Kahawae strains are likely to be adapted to coffee genotypes wherever they exist. However, further investigations are recommended to establish the possibility of the existence of physiologic races of $C$. kahawae strains. Earlier findings indicate that variation among strains of $C$. kahawae is predominantly due to differences in the degree of pathogenicity, but physiologic races do not exist $[21,23]$.

Table 6-Percentage of coffee hypocotyls per coffee genotype that indicated resistance to four Colletotrichum kahawae strains from Cameroon, Kenya, Zimbabwe and Tanzania

\begin{tabular}{|c|c|c|c|c|c|c|c|c|}
\hline \multirow{2}{*}{$\begin{array}{l}\text { Genotype/ } \\
\text { Strain }\end{array}$} & \multicolumn{2}{|c|}{ Cal } & \multicolumn{2}{|c|}{ Que 2} & \multicolumn{2}{|c|}{ Z9 } & \multicolumn{2}{|c|}{ T3 } \\
\hline & $\%$ & DIR & $\%$ & DIR & $\%$ & DIR & $\%$ & DIR \\
\hline 20497 & $10.4 \mathrm{E}$ & 37.5 & $81.3 \mathrm{C}$ & 32.9 & $55.8 \mathrm{C}$ & 36.1 & $59.5 \mathrm{C}$ & 31.5 \\
\hline 20498 & $70.7 \mathrm{~B}$ & 25 & $84.5 \mathrm{BC}$ & 32 & $55.6 \mathrm{C}$ & 48.9 & $26.0 \mathrm{~F}$ & 64.3 \\
\hline 20499 & $0.0 \mathrm{~F}$ & 100 & 25.01 & 56.8 & $2.0 \mathrm{HI}$ & 93.8 & $4.4 \mathrm{I}$ & 90.9 \\
\hline 20500 & $47.2 \mathrm{C}$ & 28 & $75.0 \mathrm{D}$ & 28.9 & $17.7 \mathrm{G}$ & 68 & $20.9 \mathrm{G}$ & 46.9 \\
\hline 20501 & $0.0 \mathrm{~F}$ & 100 & $73.9 \mathrm{D}$ & 28.8 & $37.5 \mathrm{D}$ & 24.9 & $34.3 \mathrm{E}$ & 37.5 \\
\hline 20502 & $0.0 \mathrm{~F}$ & 95.8 & $46.7 \mathrm{G}$ & 35.6 & $5.9 \mathrm{H}$ & 56.8 & $20.8 \mathrm{G}$ & 47 \\
\hline 20503 & $4.6 \mathrm{~F}$ & 76.7 & $89.1 \mathrm{AB}$ & 35.4 & $31.6 \mathrm{E}$ & 55.4 & $79.8 \mathrm{~B}$ & 34 \\
\hline 20504 & $16.7 \mathrm{D}$ & 51.9 & $60.9 \mathrm{E}$ & 41.7 & $25.0 \mathrm{~F}$ & 63.3 & $22.5 \mathrm{FG}$ & 63 \\
\hline 20505 & $4.0 \mathrm{~F}$ & 92.9 & $36.3 \mathrm{H}$ & 49.9 & $0.0 \mathrm{I}$ & 88.5 & $10.5 \mathrm{H}$ & 58.4 \\
\hline 20506 & $2.4 \mathrm{~F}$ & 93.8 & $72.9 \mathrm{D}$ & 41.9 & 0.01 & 91 & 48.3 D & 42.7 \\
\hline 20507 & $4.0 \mathrm{~F}$ & 75 & $60.1 \mathrm{E}$ & 40.8 & $23.9 \mathrm{~F}$ & 72.6 & $35.5 \mathrm{E}$ & 36.5 \\
\hline 20508 & $0.0 \mathrm{~F}$ & 100 & $87.5 \mathrm{AB}$ & 29.2 & $36.7 \mathrm{D}$ & 63.5 & $59.3 \mathrm{C}$ & 37.5 \\
\hline 20509 & $79.5 \mathrm{~A}$ & 25 & $92.0 \mathrm{~A}$ & 25 & $92.1 \mathrm{~A}$ & 25 & 25.1 FG & 63.1 \\
\hline 20510 & $4.2 \mathrm{~F}$ & 79.9 & $89.2 A B$ & 27.7 & $66.1 \mathrm{~B}$ & 27.3 & $97.9 \mathrm{~A}$ & 26.1 \\
\hline 20511 & $0.0 \mathrm{~F}$ & 100 & $55.2 \mathrm{~F}$ & $0.0 \mathrm{~J}$ & 0.01 & 100 & 0.01 & 100 \\
\hline 20512 & $2.0 \mathrm{~F}$ & 92.9 & 64.1 & 100 & $2.3 \mathrm{HI}$ & 82.5 & 0.01 & 96.9 \\
\hline DMRT & \multirow{2}{*}{\multicolumn{2}{|c|}{$\begin{array}{c}4.6 \\
15.4\end{array}$}} & \multirow{2}{*}{\multicolumn{2}{|c|}{$\begin{array}{c}4.6 \\
64.4\end{array}$}} & \multirow{2}{*}{\multicolumn{2}{|c|}{$\begin{array}{c}4.6 \\
28.3\end{array}$}} & \multicolumn{2}{|c|}{4.6} \\
\hline ean & & & & & & & & \\
\hline S.E & \multicolumn{2}{|c|}{6.5} & \multicolumn{2}{|c|}{6.6} & \multicolumn{2}{|c|}{6.9} & \multicolumn{2}{|c|}{7.1} \\
\hline
\end{tabular}

Means followed by small letter within the same column do not differ significantly following mean separation by Duncan's Multiple Range Test. $D I R=$ Disease Intensity Reaction, S.D = Standard deviation, SE = Standard error DIR 0-25, Resistant; 26-50, moderately resistant; 51-75, moderately susceptible; 76-100 susceptible. Ca1, Que2, Z9 and T3 = C. kahawae strains \% = Percentage of infected coffee hypocotyls.

The mean percentage of coffee berries per genotypes that were susceptible to C. kahawae strains are presented in [Table-7]. Susceptiblity of the coffee genotypes to $C$. kahawae differed significantly across genotypes ( $P £ 0.05$ ). Coffee genotypes 20498, 20499, 20504, 20509 and 20510 were all slightly susceptible to CBD. Coffee genotypes 20511 and 20512 were significantly highly susceptible $(P £ 0.05)$ to $C B D$.

Coffee genotype 20498 and 20509 were consistently resistant to CBD for both hypocotyls and green coffee berries. This implies that coffee genotypes 20498 and 20509 are reliable sources of CBD resistance, and can be used by farmers as well as in breeding programmes.

Resistance to CBD shown by the coffee genotype 20498 may possibly be genetical as it carries the R-gene derived from Rume Sudan and T-gene from Hibrido de Timor [32]. These genes have been found to carry resistance to CBD elsewhere. Mechanical barriers during penetration may also be involved because the germination of conidia of $C$. kahawae strains on the wax surface extracted from berries of this genotype was low [Fig-1]. Data from this study support the finding of Akinsanmi, et al [1], who reported that the distribution pattern of resistance in coffee is possibly caused by more than one mechanism. Lin, et al [13] reported that genes for $\mathrm{CBD}$ resistance in coffee were pathogen specific. When reevaluating the resistance of Coffea arabica cv. Ruiru II with different strains of $C$. kahawae, Omondi, et al [22] reported that broad based resistance combining several genes in one plant may cause durable resistance. Other authors have also reported the importance of resistance genes in coffee to confer durability under different environment. Omondi, et al [22] and Noir, et al [19] reported that hypersensitive-like reactions caused by resistant genes have been shown in some $C$. arabica varieties against Meloidogyne exigna. Also studies shown the presence of resistance genes in some coffee plants as being due to hypersensitive reaction during infection by Hemileia vastatrix $[8,9,27]$. This study confirms the existence of potential CBD resistant coffee genotypes within Lyamungu germplasm collection, which can be used to improve the coffee breeding programme in Tanzania.

Table 7- Mean percent berries of Coffea arabica genotypes indicating percentage susceptibility to Colletotrichum kahawae strains from coffee ecosystems in Tanzania

\begin{tabular}{lcccc|} 
Coffee Genotype & $2006 / 14$ (T3) & $2006 / 22(T 12)$ & $2006 / 12(T 26)$ & $2006 / 8(T 4)$ \\
20497 & $11.6 \mathrm{BCDE}$ & $5.7 \mathrm{BC}$ & $5.5 \mathrm{D}$ & $11.1 \mathrm{CD}$ \\
20498 & $3.1 \mathrm{FG}$ & $3.6 \mathrm{BC}$ & $0.0 \mathrm{E}$ & $0.0 \mathrm{G}$ \\
20499 & $0.0 \mathrm{G}$ & $0.0 \mathrm{D}$ & $0.0 \mathrm{E}$ & $4.2 \mathrm{EFG}$ \\
20500 & $7.9 \mathrm{DEF}$ & $3.6 \mathrm{CD}$ & $0.0 \mathrm{E}$ & $0.0 \mathrm{G}$ \\
20501 & $14.3 \mathrm{BC}$ & $5.3 \mathrm{BC}$ & $3.0 \mathrm{DE}$ & $0.0 \mathrm{G}$ \\
20502 & $7.1 \mathrm{EF}$ & $0.0 \mathrm{D}$ & $0.0 \mathrm{E}$ & $8.9 \mathrm{DE}$ \\
20503 & $9.5 \mathrm{CDE}$ & $0.0 \mathrm{D}$ & $21.0 \mathrm{C}$ & $14.3 \mathrm{C}$ \\
20504 & $0.0 \mathrm{G}$ & $6.7 \mathrm{BC}$ & $1.6 \mathrm{DE}$ & $5.7 \mathrm{EF}$ \\
20505 & $0.8 \mathrm{G}$ & $10.0 \mathrm{~B}$ & $3.3 \mathrm{DE}$ & $4.0 \mathrm{EFG}$ \\
20506 & $13.6 \mathrm{BC}$ & $0.0 \mathrm{D}$ & $6.7 \mathrm{D}$ & $5.0 \mathrm{EFG}$ \\
20507 & $12.5 \mathrm{BCD}$ & $4.0 \mathrm{CD}$ & $3.9 \mathrm{DE}$ & $1.6 \mathrm{FG}$ \\
20508 & $15.4 \mathrm{~B}$ & $2.9 \mathrm{CD}$ & $4.3 \mathrm{DE}$ & $5.0 \mathrm{EFG}$ \\
20509 & $0.0 \mathrm{G}$ & $0.0 \mathrm{D}$ & $0.0 \mathrm{E}$ & $0.0 \mathrm{G}$ \\
20510 & $3.2 \mathrm{FG}$ & $2.1 \mathrm{CD}$ & $0.0 \mathrm{E}$ & $0.0 \mathrm{G}$ \\
20511 & $92.5 \mathrm{~A}$ & $65.0 \mathrm{~A}$ & $86.7 \mathrm{~A}$ & $82.3 \mathrm{~A}$ \\
20512 & $88.4 \mathrm{~A}$ & $61.1 \mathrm{~A}$ & $77.8 \mathrm{~A}$ & $73.1 \mathrm{~B}$ \\
DMRT (P£0.05) & 4.6 & 4.6 & 4.6 & 4.6 \\
Mean & 17.5 & 10.6 & 13.4 & 3.5 \\
S.E & 7.3 & 5.2 & 6.9 & 6.4 \\
\hline
\end{tabular}

Means followed by small letter within the same column do not differ significantly following mean separation by Duncan's Multiple Range Test. 2006/14, 2006/22, 2006/12 and 2006/8 = C. kahawae strains

\section{Determination of Pathogenicity of Colletotrichum kahawae Strains}

\section{Determination of Pathogenicity of Colletotrichum kahawae Strains on Detached Green Coffee Berries}

Pathogenicity of $C$. kahawae strains were tested on detached green expanding coffee berries at Lyamungu, Tanzania based on days of the first observable symptom appearance, enlargement of lesions, sporulation capacity and percentage of the infected berries. The data reveal that all $25 \mathrm{C}$. kahawae strains infected green coffee berries with some variations in the level of pathogenicity. Strains 2006/26, 2006/5 and 2006/7 had induced CBD symptoms on green coffee berries significantly earlier (at 2 days) than was the case with the rest of the strains $(P<0.05)$ [Table-8]. Strains 2006/27 and $2006 / 6$ took five days to induce CBD symptoms on green coffee berries. On the same token, strains 2006/20 and 2006/1 induced significantly larger lesions than did the rest of the strains. Strain $2006 / 27$ induced the smallest lesions $(P<0.05)$. Sporulation of $C$. kahawae appeared 5 days early on green berries for strains 2006/1 and 2006/7, while strains 2006/25 and 2006/27 sporulated 9 days late. The number of days to sporulation for the rest of the strains 
was not significantly different $(\mathrm{P} £ 0.05)$ [Table-8]. Sporulation capacity for C. kahawae strain 2006/14 was significantly higher $(P<$ 0.05 ) than was the case in the rest of the strains. Strains $2006 / 15$ and 2006/13 sporulated the least [Table-8].

Data in [Table-8] indicate that the $25 \mathrm{C}$. kahawae strains differed significantly $(P<0.05)$ in the number of days to first symptoms appearance, lesion size $(\mathrm{mm})$, days to sporulation, sporulation capacity $($ spores $/ \mathrm{ml}$ ) and percent infected berries, reflecting differences in pathogenicity (ability to infect) and virulence (degree of infection).

Strain 2006/14 (T3) was consistently observed to be highly pathogenic to green coffee berries of $C$. arabica genotypes used in this study. The high pathogenicity ability was attributed to high sporulation capacities [Table-8] which usually lead to a high percentage of germinated conidia and appressorium formation in the host tissues, resulting high infection levels. Accordingly, Silva, et al [26] report that $\mathrm{C}$. kahawae strain $\mathrm{Ca} 1$ exhibit high virulence because of high sporulation capacity and germination of conidia in the host tissues. Omondi, et al [23] when studying the degree of pathogenicity using C. kahawae strains from Ethiopia and Kenya found virulence variability among the strains. This study has provided useful preliminary information on strengthening the coffee breeding programme in Tanzania. Strain 2006/14 of C. kahawae should be used in future studies for screening resistance of $C$. arabica.

Table 8- Virulence of Colletotrichum kahawae strains from different ecosystems on green expanding coffee berries

\begin{tabular}{|c|c|c|c|c|c|c|}
\hline Strain & $\begin{array}{l}\text { Location } \\
\text { Collection of } \\
\text { isolate }\end{array}$ & $\begin{array}{c}\text { First } \\
\text { symptoms } \\
\text { appearance } \\
\text { (days) }\end{array}$ & $\begin{array}{l}\text { Lesion } \\
\text { size* } \\
(\mathrm{mm})\end{array}$ & $\begin{array}{l}\text { Sporula- } \\
\text { tion } \\
\text { (days) }\end{array}$ & $\begin{array}{c}\text { Sporulation } \\
\text { capacity* } \\
\text { (Spores/ml) }\end{array}$ & $\begin{array}{c}\text { Infected } \\
\text { Berries } \\
(\%)^{*}\end{array}$ \\
\hline $2006 / 25$ & Lyamungu & $4 \mathrm{~B}$ & $2-3 E$ & 9:00 AM & $20 \mathrm{C}$ & $20 P$ \\
\hline $2006 / 26$ & Lyamungu & $2 \mathrm{D}$ & $3-8 \mathrm{C}$ & $7 \mathrm{~B}$ & $410 \mathrm{H}$ & $80 \mathrm{E}$ \\
\hline 2006/27 & Lyamungu & 5:00 AM & $1-2 \mathrm{~F}$ & 9:00 AM & $40 \mathrm{~S}$ & $90 \mathrm{C}$ \\
\hline 2006/28 & Lyamungu & $3 C$ & $2-10 B$ & $7 B$ & $750 \mathrm{C}$ & $65 \mathrm{H}$ \\
\hline $2006 / 29$ & Lyamungu & $3 C$ & $2-7 \mathrm{C}$ & $7 \mathrm{~B}$ & $260 \mathrm{~J}$ & $95 \mathrm{~B}$ \\
\hline 2006/14 & Kibosho-Kombo & $3 C$ & $2-7 \mathrm{C}$ & $7 \mathrm{~B}$ & $850 \mathrm{~A}$ & $100 \mathrm{~A}$ \\
\hline 2006/15 & Marere-Mwika & $3 C$ & $2-5 \mathrm{E}$ & $7 B$ & $0 \mathrm{R}$ & $90 \mathrm{C}$ \\
\hline 2006/16 & Machame Foo & $3 C$ & $2-3 E$ & $7 \mathrm{~B}$ & $120 P$ & 250 \\
\hline 2006/19 & Rombo Mokala Juu & $3 C$ & $2-8 \mathrm{C}$ & $7 \mathrm{~B}$ & $220 \mathrm{~K}$ & $70 \mathrm{G}$ \\
\hline $2006 / 20$ & Kerio & $3 C$ & $6-10 \mathrm{~A}$ & $7 B$ & $50 R$ & $40 \mathrm{~L}$ \\
\hline 2006/21 & Babati Haraa & $3 C$ & $3-8 \mathrm{C}$ & $7 \mathrm{~B}$ & $445 \mathrm{G}$ & $35 \mathrm{M}$ \\
\hline 2006/22 & Karatu Ngorongoro & $3 C$ & $3-10 B$ & $7 \mathrm{~B}$ & $790 \mathrm{~B}$ & $75 \mathrm{~F}$ \\
\hline $2006 / 4$ & Mbozi Mahenje & $3 C$ & $3-6 \mathrm{C}$ & $7 \mathrm{~B}$ & $30 \mathrm{~T}$ & $50 \mathrm{~K}$ \\
\hline $2006 / 5$ & Mbozi Malenje & $2 \mathrm{D}$ & $3-8 \mathrm{C}$ & $7 B$ & $140 \mathrm{~N}$ & $80 \mathrm{E}$ \\
\hline $2006 / 6$ & Mbozi General & 5:00 AM & $2-3 C$ & $7 \mathrm{~B}$ & $450 \mathrm{~F}$ & $20 \mathrm{P}$ \\
\hline $2006 / 7$ & Mbinga Mbuji & $2 \mathrm{D}$ & $2-4 \mathrm{E}$ & $5 \mathrm{C}$ & $290 I$ & $65 \mathrm{H}$ \\
\hline 2006/8 & Mbinga Mkumbi & $3 C$ & $3-10 B$ & $7 B$ & $480 \mathrm{E}$ & $35 \mathrm{M}$ \\
\hline $2006 / 9$ & Mbinga Ngima & $4 B$ & $2-4 \mathrm{E}$ & $7 \mathrm{~B}$ & $150 \mathrm{M}$ & $55 \mathrm{~J}$ \\
\hline $2006 / 10$ & Mbinga Lugari & $3 C$ & $2-7 \mathrm{C}$ & $7 B$ & $100 Q$ & $30 \mathrm{~N}$ \\
\hline 2006/11 & Mbinga Myanje & $3 C$ & $2-6 \mathrm{D}$ & $7 \mathrm{~B}$ & $200 \mathrm{~L}$ & $50 \mathrm{~K}$ \\
\hline 2006/1 & Mbeya Lunji & $3 C$ & $3-12 \mathrm{~A}$ & $5 \mathrm{C}$ & $20 \mathrm{~V}$ & $85 \mathrm{D}$ \\
\hline $2006 / 23$ & Mbeya Lunji 4 & $4 \mathrm{~B}$ & $2-3 E$ & $7 \mathrm{~B}$ & 1300 & 601 \\
\hline 2006/24 & Tarime Kimusi & $3 C$ & $3-7 \mathrm{C}$ & $7 B$ & $150 \mathrm{M}$ & $70 \mathrm{G}$ \\
\hline 2006/12 & Kigoma Kalinzi & $3 C$ & $3-8 \mathrm{C}$ & $7 \mathrm{~B}$ & $520 \mathrm{D}$ & $85 \mathrm{D}$ \\
\hline $\begin{array}{l}\text { 2006/13 } \\
\text { DMRT (P }\end{array}$ & $\begin{array}{l}\text { Kigoma } \\
<<0.05)\end{array}$ & $4 B$ & $2-3 E$ & $7 \mathrm{~B}$ & $13 \mathrm{~V}$ & $\begin{array}{l}90 \mathrm{C} \\
0.82\end{array}$ \\
\hline SE & & & & & & 0.28 \\
\hline
\end{tabular}

${ }^{*}$ Evaluated 7 days after inoculation

Means followed by a common letter within a column do not differ significantly according to DMRT ( $P £ 0.05)$.

\section{Determination of Pathogenicity of Colletotrichum kahawae Strains on Coffee Hypocotyls}

Strains of $C$. kahawae were selected from three coffee growing zones based on their pathogenicity on detached green coffee ber- ries. The strains included; 2006/14 and 2006/22 from Northern Tanzania, 2006/12 from Kigoma and 2006/8 from Southern Tanzania. [Fig-5] presents results of the reaction of these strains to coffee hypocotyls of the susceptible variety N39. Strain 2006/14 was more pathogenic than strains 2006/12, 2006/8 and 2006/22 $(P<0.05)$ [Table-9]. This strain rapidly caused seedlings to shrivel and die within 7 days after inoculation and it took 14 days for other strains to kill the same coffee variety. Strain 2006/22 produced brown and black lesions only on coffee hypocotyls.

Results in [Fig-5] and [Table-9] confirm that C. kahawae strain 2006/14 was the most pathogenic strain than the rest of the strains. The strain rapidly caused coffee hypocotyls to shrivel and die within 7 days after inoculation, while other strains took 14 days for the same results. This signifies that the strain can be used very successfully to determine initial CBD resistance information of the coffee hybrids that is pre-selection for CBD resistance using hypocotyls [33].

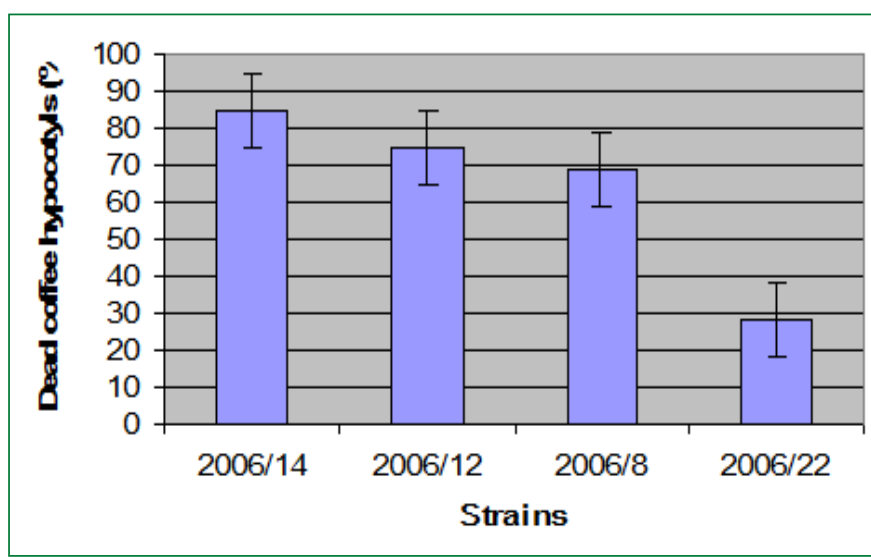

Fig. 5- Pathogenicity of four Colletotrichum kahawae strains on coffee hypocotyls of genotype N39

Table 9- Reaction of coffee hypocotyls of N39 susceptible varieties to four most pathogenic Colletotrichum kahawae strains from four coffee ecosystems in Tanzania

\begin{tabular}{|c|c|c|c|c|}
\hline \multicolumn{2}{|c|}{ Strain Code } & I pation & \multirow{2}{*}{\multicolumn{2}{|c|}{ Percent Dead Hypocotyls Days to Shrivel }} \\
\hline TaCRI & CIFC & Loctation & & \\
\hline 2006/14 & T3 & Kibosho-Kombo & $85 \mathrm{~A}$ & 7 \\
\hline $2006 / 22$ & T2 & Karatu & $28 \mathrm{D}$ & 14 \\
\hline $2006 / 12$ & T26 & Kigoma-Kalinzi & $75 B$ & 14 \\
\hline 2006/8 & T4 & Mbinga-Mkumbi & $69 \mathrm{C}$ & 14 \\
\hline \multicolumn{2}{|l|}{ Mean } & \multicolumn{3}{|c|}{64.25} \\
\hline \multicolumn{2}{|l|}{$S_{x}$} & \multicolumn{3}{|c|}{1.28} \\
\hline \multicolumn{2}{|c|}{ DMRT $(\mathrm{P}<0.05)$} & & 5.8 & \\
\hline
\end{tabular}

TaCRI = Tanzania Coffee Research Institute, Moshi, Tanzania; CIFC = Centro de Investigacao das Ferrugens do Cafeeiro, Portugal

Means followed by a common letter within a column do not differ significantly according to DMRT ( $P £ 0.05)$.

At CIFC Portugal, the virulence of strain 2006/14 (T3) from Tanzania was compared to $C$. kahawae strain Ca1, Qu2 and Z9. All strains were pathogenic on hypocotyls of N 39 [Table-9]. Accordingly, Varzea, et al [36] reported that $C$. kahawae strain $\mathrm{Ca} 1$ is the most pathogenic strain compared to other strains of the pathogen because of high sporulation capacity and rapid conidial germination on the host tissues. Strain 2006/14 (T3) demonstrated equal pathogenic to Ca1 [Table-10], [Fig-6]. Therefore, C. kahawae strain 2006/14 can be used in screening resistant to CBD in Tanzania. 
Table 10- Reaction of four Colletotrichum kahawae strains on coffee from Cameroon Ca1, Kenya Qu2, Zimbabwe Z9 and Tanzania 2006/14 (T3) on coffee hypocotyls of cultivar N 39

\begin{tabular}{|llll|} 
Strain & \multicolumn{2}{c}{ Hypocotyl reaction } & \multicolumn{1}{c|}{$\begin{array}{l}\text { Percent proportion of } \\
\text { scabs \& active lesions }\end{array}$} \\
\hline Ca1 & Brown (scab) lays) & $100 \%$ actives \\
Qu2 & Brown (scab) lesions Dead hypocotyls & 10xtures of scabs and actives & $12 \%$ scabs, $88 \%$ dead \\
Z9 & Brown (scab) lesions Mixtures of scabs and actives & $44 \%$ scab, $56 \%$ dead \\
T3 & Scabs and actives & Dead hypocotyls & $100 \%$ actives \\
\hline
\end{tabular}

The number of coffee hypocotyls killed by the four $C$. kahawae strains was also assessed 9 days after artificial inoculation. [Fig-5] shows the percentage dead coffee hypocotyls of the cultivar N39 by Ca1, Qu2, Z9 and T3 (2006/14). The higher percentage of dead coffee hypocotyls were recorded on $C$. kahawae strains $\mathrm{Ca} 1$ and 2006/14 than in the Qu2 and Z9 strains. This confirms further the pathogenicity of $C$. kahawae strain 2006/14.

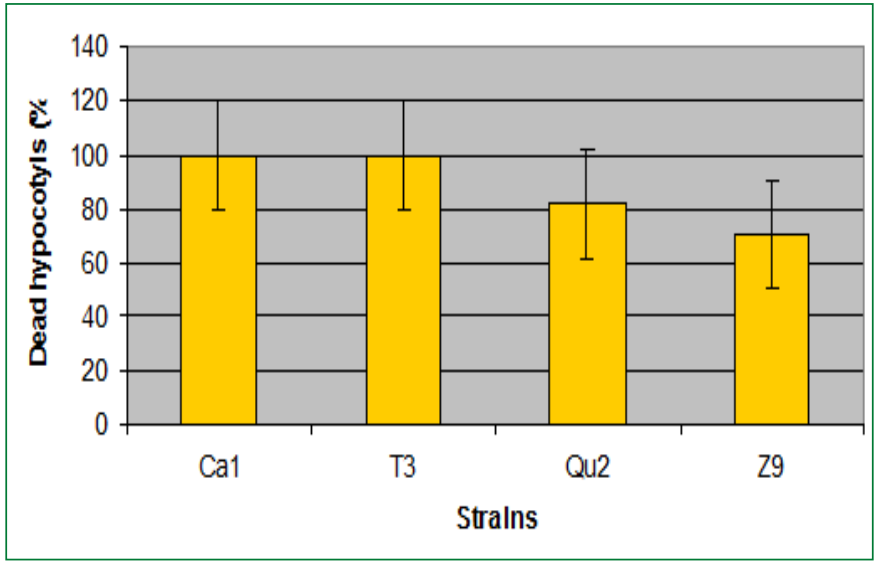

Fig 6- Percentage of dead coffee hypocotyls of cultivar N 39 caused by Colletotrichum kahawae strains nine days after artificial inoculation

\section{Conclusions}

The nature of resistance of Lyamungu coffee hybrids to $C$. kahawae strains was confirmed to have been influenced by surface wax from green berries of $C$. arabica genotypes and deposition of polysaccharide materials at the sites of attempted penetration by the pathogen. More studies are needed to confirm the involvement of antifungal compounds in the nature resistance of Lyamungu coffee genotypes to CBD. This study also indicates that $C$. kahawae strains are likely to have adapted to the coffee genotypes. However, further investigations are needed to establish the possibility of the existence of physiologic races of the C. kahawae strains.

The study also found out that some of the $C$. kahawae strains are highly pathogenic while others were less virulent when compared to strains from Cameroon, Zimbabwe and Kenya. The most pathogenic strain of C. kahawae found in Tanzania was 2006/14 (T3). The strain showed significant pathogenicity because of the high sporulation capacity and earliness in causing CBD symptoms appearance both on detached coffee green berries and hypocotyls in laboratory tests. From these findings it can therefore be concluded that high sporulation capacity and earliness to CBD symptom appearance are important factors to consider in selecting virulent $C$. kahawae strains for screening resistance of $C$. arabica varieties to the pathogen.

\section{Acknowledgement}

We wish to thank the European Union in Tanzania for their generous financial support through Coffee Research and Technology Support Programme which enabled us to publish this work. We also thank Tanzanian coffee growers who contribute to our research and development activities. The authors are indebted to CIFC for valuable technical input and advice which enabled successful write-up of this scientific paper. Our gratitude is also extended to SUA for the reviewing and supervision of the paper. We wish to thank TaCRI BOD, its Technical Advisory Panel and management for direct contribution to the successful documentation of the work. It is also our pleasure to thank Mrs. J.M. Urassa for isolation of the C. kahawae strains and Ms. Sandra for further purification of the strains.

\section{References}

[1] Akinsanmi D., Backhouse D., Simpfendorfer S. and Chakrabosty S. (2006) Journal of Phytopathology, 154 (9), 513521.

[2] Anthony F., Topart P., Martinez A., Silva M. and Nicole M. (2005) Plant Pathology, 52, 97-103.

[3] Chen Z., Franco C.F., Baptista R.P. , Cabral J.M.S., Coelho A.V., Rodrigues C.J. and Melo E.P. (2007) Applied Microbiol. Biotechmol., 73, 1306-1313.

[4] Chen Z., Liang J., Zhang C., and Rodriques C.J. (2006) Biotechnol. Lett., 28, 1637-1640.

[5] Chen Z.J., Nunes M.A., Silva M.C. and Rodriques C.J. (2004) Mycologia, 96, 199-1208.

[6] Chen Z.J., Ribeiro A., Silva M.C., Santos P., Guerra-Guimaraes L., Gouveia M., Fernandez D.R. (2003) Physiological Molecular Plant Pathology, 63, 181-189.

[7] Cruickshank R.H. (1995) Journal of Phytopathology, 143, 519524.

[8] Fernandez D., Santos P., Agostini C., Bon M.C., Petitot A.N., Silva M.C., Guerra-Guimaraes L., Ribeiro A., Argout X. and Nicole M. (2004) Molecular Plant Pathology, 5(6), 527-536.

[9] Ganesh D., Petitol A.S., Silva M.C., Alary R., Lecouls A.C. and Fernandez D. (2006) Plant science, 170, 1045-1051.

[10]Gichuru E. (1997) A review. Kenya Coffee, 727, 2441-2444.

[11]Hocking D. (1967) East Africa Agricultural and Forestry Journal, $32,371-374$

[12]Kilambo D., Swai F., Nyange N., Kipokola T., Mtenga D. and Charmetant P. (1999) Proceedings of the 18th International scientific conference on coffee (ASIC), Helsinki, Finland, 508511.

[13]Lin C., Muller L.A., Carthy J.Mc., Crouzillat D., Petiard Y. and Tanksley S.D. (2005) Theory of Applied Genetics, 112, 114130.

[14]Mansfield J., Bennett M., Bstwick C. and Woods-Toer A. (1997) The Gene-For-Gene Relationship in Plant-Parasite interactions, CABI International. 265-291.

[15]Masaba D.M. and van der Vossen H.A.M. (1982) Netherlands Journal of Plant Pathology, 88, 19-32.

[16]Mulinge S.K. (1970) Annals of Applied Biology, 66, 269-276.

[17]Ndondi R.V. and Nyange N.E. (1990) Research and Training Newsletter, V(1), 9.

[18]Ngulu F.S. and Kilambo D.L. (1994) Coffee Pathology annual 
report, 4.

[19]Noir S., Anthony F., Bertrand B., Combes Mc., and Lashermes P. (2003) Plant Pathology, 52, 97-103.

[20]OH B.J., Kim K.D. and Kim Y.S. (1999) Journal of Phytopathology, 147, 547-552.

[21]Omondi C., Agwanda C.D. and Gichuru E.K. (2004) Proceedings of the 20th International Conference on Coffee Science (ASIC), Bangalore, India.

[22] Omondi C.O., Ayiecho P.O., Mwang'ombe A.W. and Hindorf H. (2001) Euphytica, 121, 19-24.

[23]Omondi C.O., Ayiecho P.O., Mwang'ombe A.W. and Hindorf H. (2000) Journal of Phytopathology, 148, 61-63.

[24]Pegard A., Brizzard G., Fazar A., Soucaze O., Abad P. and Djian-Caporalino C. (2005) Phytopathology, 95, 158-165.

[25]Roma E. (1997) Stage effectue au CIRAD-CP-UR DDCMontipellier, 21.

[26]Silva M.C., Varzea V., Guerra-Guimaraes L., Azinheira H.G., Fernandez D., Petitot A., Bertrand B., Lashermes P. and Nicole M. (2006) Brazilian Journal of Plant Physiology, 18 (1), 119147.

[27]Silva M.C., Nicole M., Gurra-Guimaraes L. and Rodriques C.J. (2002) Physiological and molecular Plant Pathology, 60, 169183.

[28]Silva M.C., Varzea V.M.P., Rijo L., Rodriques C.J. and Moreno G. (1999) Proceedings of the $18^{\text {th }}$ International Conference on Coffee Science (ASIC), 512-515, Helsinki, Finland.

[29]Staskawicz B. (2005) Plant Physiology, 125, 73-76.

[30]Steiner K.G. (1972) Kenya Coffee, 37, 179.

[31]Van der Graaff N.A. (1981) Euphytica, 31, 735-740.

[32]Van der Vossen H.A.M. and Walyaro D.J. (1980) Euphytica, 29, 777-791.

[33]Van der Vossen H.A.M., Cook R.T.A. and Murakaru G.N.W. (1976) Euphytica, 25, 733-745.

[34]Van der Vossen (1985) Coffee Selection and Breeding, Coffee: Botany, Biochemistry and Production of Beans and Beverage. Croom Helm, London.

[35]Varzea V.M.P., Rodriques C.J. and Silva M.C. (2002) International Synposium on Durable resistance: key to sustainable agriculture, Ede-Wageningen, Holanda. 34.

[36]Varzea V.M.P., Rodriques C.J., Silva M.C., Pedro J.P. and Marques D.M. (1999) Proceedings of the $18^{\text {th }}$ International Conference on Coffee Science (ASIC), Helsink, Finland. 516-519. 